\title{
Socio-Economic and Demographic Determinants of HIV Status among HIV Infected Older Adults (50-64 Years) In Botswana: Evidence From 2013 Botswana AIDS Impact Survey (BAIS IV)
}

\author{
Njoku Ola Ama ${ }^{1 *}$, Vijai Kumar Dwivedi ${ }^{1}$, Sheila Shaibu ${ }^{2}$ and Denise Burnette ${ }^{3}$ \\ ${ }^{1}$ Department of Statistics, University of Botswana, Gaborone, Botswana \\ ${ }^{2}$ School of Nursing Education, Faculty of Health Sciences, University of Botswana, Botswana \\ ${ }^{3}$ School of Social Work, Columbia University, New York, USA
}

\begin{abstract}
A stratified two-stage probability sample design was used in selecting a total of 459 Enumeration areas and 8,275 households drawn systematically for the study with the aim to describe the characteristics of the HIV infected older adults in Botswana and determine how the HIV status of the older adults is influenced by their socio-economic and demographic characteristics. Household and the individual questionnaires developed using the opinions of professionals, users of statistics, as well as experiences from the pre-test formed the instrument for the study. The results revealed that $23.2 \%$ of the older adults $50-64$ years $(25.5 \%$, males and $21.5 \%$, females) were HIV positive. An overwhelming majority of the males $(88.7 \%)$ and females $(83.3 \%)$ had either no education or primary education. About half of the males $(50.9 \%)$ and $19 \%$ of the females were married while the majority of the females $(43.9 \%)$ were never married. All the socio-economic and demographic variables significantly $(p<0.01)$ predicted the probability of an older adult being HIV positive. The older adults with secondary education and higher education were respectively, 65.5 times and 1.8 times more likely to be HIV positive. Type of locality had significant impact in the determination of HIV status of the older adults. There are significant association between the socio-economic, demographic variables and the risk behaviours (use of condom and adherence to ARV treatment). Education, focusing on prevention and education initiatives for HIV and AIDS, including peer education, media awareness campaigns, group workshops, publications for mass consumption, individual and couple counselling is very much desired and should be provided to the older adults.
\end{abstract}

Keywords: HIV and AIDS; Older adults; Socio-economic; Demographic characteristics

\section{Introduction}

The concept of older adult has a relatively recent usage, and has appeared as an alternative to the classic person of senior and elder. An older adult is that individual who is in the last stage of life, which follows after adulthood and that precedes the death of the person. Interest in this paper is on those 50 years and over [1,2].

Despite the very significant global attention to address the HIV epidemic, the HIV infection among older adults, particularly in subSaharan Africa, has been neglected [3]. The Joint United Nations Programme on HIV and AIDS (UNAIDS) and other prominent sources of data and report on prevalence of HIV only address those aged 15-49 years, and the indicators used by the United Nations General Assembly Special Session focus predominantly on the same age group [4]. The burden of disease among those aged 50 years and older is almost always ignored and this represents a significant blind spot in the global response to the epidemic of HIV infection and acquired immunodeficiency syndrome (AIDS). There is, therefore, a paucity of data on HIV infection in people aged 50 years or older. Current statistics, [2], show that : worldwide, an estimated 3.6 [3.2-3.9] million people aged 50 years and older are living with HIV; $10 \%$ of the adult population living with HIV in low- and middle-income countries are aged 50 years or older; in 2012 there were an estimated 2.9 [2.63.1] million people aged 50 years and over living with HIV in low- and middle-income countries; in high-income countries, approximately $30 \%$ of all adults living with HIV are aged 50 years and over; and the proportion of adults living with HIV who are aged 50 years and older has increased in all regions, at varying rates, since 2007 [2].

There are few HIV prevention efforts that target older adults. Likely reasons for this oversight include misconceptions of low incidence and prevalence rates, and misperceptions about vulnerability to HIV infection and about later-life sexuality among older adults. The primary behavioural risk factor is sexual activity without condoms, accounting for more than $60 \%$ of infections, and to a lesser extent alcohol abuse and injection drug use [5]. Although older adults engage in high-risk behaviours, they are less likely to see themselves as at-risk, less likely to adopt safe sexual and needle sharing behaviours and more likely to be diagnosed late in the disease process. In part, this is because health care providers do not routinely screen for HIV in older patients [6] and in the case of Botswana, there is the taboo behind younger people discussing issues of sex and sexuality with older adults. Sero-positive older adults thus experience more rapid disease progression, lower immunity recovery [7] and worse survival rates than younger adults, and they may not even know that they are infecting others [8-10]. Some of the symptoms of normal aging such as fatigue, weight loss and mental confusion also occur in the diagnosis for AIDS making it difficult for Physicians to easily diagnose AIDS in the older adults [11].

Age-related physiological changes also increase the risk of HIV

*Corresponding author: Njoku Ola Ama, Department of Statistics, University of Botswana, Gaborone, Botswana, Tel: 267 3552705; E-mail: njoku52@gmail.com, amano@mopipi.ub.bw

Received January 24, 2015; Accepted March 31, 2015; Published April 11, 2015

Citation: Ama NO, Dwivedi VK, Shaibu S, Burnette D (2015) Socio-Economic and Demographic Determinants of HIV Status among HIV Infected Older Adults (50-64 Years) In Botswana: Evidence From 2013 Botswana AIDS Impact Survey (BAIS IV). J AIDS Clin Res 6: 448. doi:10.4172/2155-6113.1000448

Copyright: ( 2015 Ama NO, et al. This is an open-access article distributed under the terms of the Creative Commons Attribution License, which permits unrestricted use, distribution, and reproduction in any medium, provided the original author and source are credited. 
Citation: Ama NO, Dwivedi VK, Shaibu S, Burnette D (2015) Socio-Economic and Demographic Determinants of HIV Status among HIV Infected Older Adults (50-64 Years) In Botswana: Evidence From 2013 Botswana AIDS Impact Survey (BAIS IV). J AIDS Clin Res 6: 448. doi:10.4172/21556113.1000448

Page 2 of 9

infection, and declining immunity diminishes the ability to defend against exposure to microorganisms and other stressors in the older adults [12]. For women, decreased oestrogen leads to vaginal dryness and thinning, leaving them prone to abrasions and tears that increase risk of HIV infection [13]. Post-menopausal women who no longer use contraception may not use HIV protection such as condoms [12]. Another major concern is aging-related and HIV-related co-morbidities [14-17]. These conditions, and iatrogenic effects of treatment, can hasten the disease process, complicate disease and symptom management, and lower the odds of survival $[18,19]$.

Older persons with HIV infection share some psychosocial issues with their younger counterparts, i.e., stigma, disclosure conflicts, depression and social support issues, although the etiology, intensity and outcomes may vary $[19,20]$. Adults in the age group 50-64, although approaching retirement, are usually still working; some are still engaged in raising families, and some are beginning to experience chronic health problems typical of older adults. The age group 55-64 serves as a useful benchmark for assessing the patterns in health characteristics observed among adults in the older groups [21].

As the Botswana population continues to age, it is important to be aware of specific challenges faced by older Batswana and to determine the factors that affect the HIV status of the older adults. The 2013 BAIS IV preliminary report indicates that of the older adults (50 years and older) who tested for HIV and declared their results, $23.2 \%$ were HIV positive (25.5\% of males, $21.5 \%$ of females) and the main way of transmission is sexual activity (96.4\% of them had sex in the past 12 months) [22]. This proportion of older adults with HIV is expected to grow due to increased life expectancy as AIDS related mortality rates decline both at individual and population levels due to ART. Survival is also expected to exceed 15-20 years from (i) sero-conversion [23,24], (ii) already infected entrants into this cohorts from younger age groups ( $<50$ years), (iii) late diagnosis of patients who remain unaware of their status for a long time [25-27] and (iv) an increase in the number of people infected with HIV in later stages of life [28]. Tlou [29] conducted a qualitative and quantitative study on older adults in Botswana to identify their knowledge, experiences and attitudes towards HIV and AIDS. The qualitative study using 24 interviews showed that older people were marginalized by government messages on HIV and AIDS. The author recommended that a culturally sensitive peer education intervention for AIDS prevention, care and control for older people be developed.

A study by Negin and Cumming [3] estimated that there are three million HIV positive people in Sub-Saharan Africa aged 50 years and older, representing more than $14 \%$ of those over the age of 15 years infected and suggesting that increased attention is desirable for the older adults. In South Africa, a nationally representative survey reported HIV prevalence rates in the population 50 years of age and older of $10.4 \%$, $10.2 \%$ (in the age group 50-54 years), $6.2 \%, 7.7 \%$ (55-59 years), and $3.5 \%, 1.8 \%$ (60 years and older) for males and females, respectively. A more recent article, Wallrauch et al. [30], using population-based surveillance data $(\mathrm{N}=2791)$ in rural South Africa estimated the overall HIV prevalence rate in adults 50 years and older at $9.5 \%$ with highest prevalence of $29.5 \%$ in males aged $50-54$ years and $17.3 \%$ in females aged 50-54 years. A much lower HIV prevalence was reported at $2.6 \%$ in males and females aged 55-70 years in rural Cameroon, 5\% in Ethiopia and a slightly higher rate of $15 \%$ in Tanzania $[3,30,31]$.

For meaningful interventions to address older adults HIV and AIDS concerns, it is important to understand the socio-economic and demographic determinants of HIV status among the HIV positive older adults since socio-economic status is a key factor in determining the quality of life for individuals after they are affected by the virus [32].

\section{HIV and socio-economic status: A framework}

The Social determinants of health are economic and social conditions that influence the health of people and communities [33]. These conditions are shaped by the amount of money, power, and resources that people have, all of which are influenced by policy choices. Social determinants of health affect factors that are related to health outcomes. Factors related to health outcomes include: how a person develops during the first few years of life (early childhood development); how much education a person obtains; being able to get and keep a job; what kind of work a person does; having food or being able to get food (food security); having access to health services and the quality of those services; housing status; how much money a person earns; discrimination and social support [34].

Perry [35] showed that HIV is a disease that is embedded in social and economic inequity, as it affects those of lower socioeconomic status at a disproportionately high rate. Furthermore, socio-economic status is a key factor in determining the quality of life for individuals after they are affected by the virus. Those with fewer resources are often left with limited treatment options. For instance, HIV-infected people with low socio-economic status (SES) and people who are members of a racial or ethnic minority have been found to receive fewer services, including treatment with highly active antiretroviral therapy (HAART), than others [32]. A lack of socioeconomic resources is linked to the practice of riskier health behaviours, such as earlier initiation of sexual activity and less frequent use of condoms [36], which can lead to the contraction of HIV. Among women, lower social standing and the experience of life stress are associated with riskier sexual practices. This finding suggests that while ethnicity is a critical factor in the HIV and AIDS epidemic for women, social class is also an important risk factor in HIV infection [37]. Strombeck and Levy [38], and Milaszewski et al. [39] noted that the best strategy for the prevention of HIV and AIDS among older adults is education. The study by Wallrauch et al. [30] identified factors that were independently associated with positive HIV status as age 65 years and older (adjusted odds ratio $(\mathrm{OR}) 0.20, \mathrm{p}<0.05$ ); currently married ( $\mathrm{OR} 0.46, \mathrm{p}<0.05)$; being widowed, separated or divorced $(\mathrm{OR}$ $0.47, \mathrm{p}<0.05)$; and distance from household to nearest primary road, 5 $\mathrm{km}$ and over (OR 0.57, $\mathrm{p}<0.05)$. Other factors that have been identified to affect HIV and AIDS are knowledge of HIV and AIDs, its mode of infection, treatment, and information.

Unstable housing has been linked to risk for HIV infection, including drug use and unsafe sexual behaviors [40]. Individuals who are homeless or in unstable housing arrangements are significantly more likely to be infected with HIV compared to individuals in more stable housing environments [41].

\section{Botswana's progress in HIV prevention}

Botswana has made significant progress in developing and launching several national prevention, treatment and support programmes. For example, the prevention-of-mother-to-child transmission of HIV (PMTCT) was introduced in 1999; the National ART programme was implemented and rolled-out in 2002 and offers ARV free of charge to all its citizens; routine HIV testing was introduced in 2004; and HIV testing was further enhanced through an increase in voluntary counselling and testing centres throughout the country. In addition, the National Orphan Care and Home-Based Care programmes provide important care and support for those infected and affected by the epidemic. The 
Citation: Ama NO, Dwivedi VK, Shaibu S, Burnette D (2015) Socio-Economic and Demographic Determinants of HIV Status among HIV Infected Older Adults (50-64 Years) In Botswana: Evidence From 2013 Botswana AIDS Impact Survey (BAIS IV). J AIDS Clin Res 6: 448. doi:10.4172/21556113.1000448

Page 3 of 9

Multiple Concurrent Partnership Programme was launched by National AIDS Coordinating Agency (NACA) in 2009 to address one of the key drivers of HIV transmission in Botswana overlapping sexual relations with more than one person; the Safe Male Circumcision Programme, launched in 2009 by the Ministry of Health with the aim of reducing the risk of HIV transmission in males through circumcision;

These services are offered free of charge to the citizenry. There are no statistics available on how their status is affected by socio-economic and demographic characteristics of the older adults infected with HIV. This paper is an attempt to bridge that gap using data from the 2013 Botswana AIDS Impact Survey IV (BAIS IV).

BAIS is conducted every four years on a population of 6 weeks and above. The major objectives of the survey are to provide current HIV incidence and prevalence estimates among the population aged six weeks to 64 years and indicative trends in preventive behaviour among the population aged 10 to 64 years. The 2013 BAIS IV was conducted between January and April, 2013.

This paper will answer the following questions (i) What are the characteristics of the HIV infected older adults in Botswana? (ii) How is the HIV status of the older adults influenced by their socio-economic and demographic characteristics?

The findings will be useful to Statistics Botswana, the NACA and policy makers in understanding the challenges of the older adults who are HIV positive and for continuous strategic prevention and national HIV program planning. It will also be a guide for future HIV and AIDS research on the older adults.

\section{Methods}

The data for this paper were derived from the Botswana AIDS Impact Study (BAIS IV) usually conducted in 2012 by the Statistics Botswana in collaboration with NACA, Botswana. The study is conducted every four years to provide current national HIV estimates among the population aged 6 weeks through 64 years; to provide indicative trends in sexual and preventive behaviour among the population aged 10-64 years; to provide a comparison between HIV rate, behaviour, knowledge, attitude, poverty and cultural factors that are associated with the epidemic with estimates derived from previous surveys; to increase the numbers of those who know their HIV status and assist linking those found to be HIV positive to healthcare system and to produce survey results in a timely manner and ensure that the data are disseminated to a wide audience of potential users in government and non-governmental organizations within and outside Botswana.

The sampling frame was based on the 2011 Population and Housing Census. This comprised the list of all enumeration areas (EAs) together with number of households. In 2011 Census, the EAs were framed of manageable size (in terms of dwellings/households) and the primary sampling units (PSUs) were EAs.

\section{Stratification}

All the districts and major urban centres constituted the strata. In order to increase precision, the EAs were grouped according to ecological zones in rural districts, and income categories in cities/ towns. Furthermore, geographical stratification along ecological zones and income categories was done to improve the accuracy of survey data.

\section{Sample design}

A stratified two-stage probability sample design was used for the selection of the sample. The first stage was the selection of EAs as primary sampling units (PSUs) and selection was with probability proportional to measures of size (PPS), where measures of size (MOS) were the number of households in the EA as defined by the 2011 Population and Housing Census. In all 459 EAs were selected. At the second stage of sampling, the households were systematically selected from fresh list of occupied households prepared at the beginning of the survey's fieldwork (i.e. listing of households for the selected EAs). Overall 8,275 households were drawn systematically.

\section{Questionnaires and coverage}

The questionnaires were the primary recording documents of the survey. In the development of the questionnaires, the opinions of the professionals and users were invited. The final version of the questionnaires was finalized on the basis of the experiences gained from the pre-test conducted for the survey. The 2013 BAIS IV consisted of two questionnaires, namely: (i) The household questionnaire and (ii) The individual questionnaire.

\section{Fieldwork and data processing}

Smart phones were used for data collection in the survey. The information gathered was directly entered into smart phones during field enumeration period and sent to storage centre through network systems, which enabled data capture directly to data savers. This procedure saved costs and data processing period resulting in availability of the preliminary results in seven months. The data were processed and analysed using the SPSS programme.

Blood samples were collected from participants and analysed under good clinical laboratory practice (GCLP) at Botswana National Health Laboratory (NHL). All laboratory testing personnel for the study were knowledgeable of the testing procedures. New employees were trained and assessed for competence before they could handle participant samples. Documentation of training on the procedure was placed in Personnel Files. The results of the tests were then sent to Statistics Botswana.

\section{Results}

The analyses in this section are based on older adults (50-64 years) who tested positive to HIV in the BAIS IV.

\section{Socio-economic and demographic characteristics of the older adults with $\mathrm{HIV}(\mathrm{N}=22,304)$}

The results (Table 1) show that of the total population of older adults $(\mathrm{N}=96,287)$ aged $50-64$ years who tested for HIV and declared their, 22,304 (23.2\%) were HIV positive (25.5\%, males and $21.5 \%$, females). Classified by age, the HIV prevalence was $21.6 \%$ for the $50-54$ year olds, $24.9 \%$ for those aged $55-59$ years and $23.5 \%$ for those aged $60-64$ years. The HIV prevalence for males and females aged 50-54 years, 55-59 years and $60-64$ years were, respectively, $19.8 \%, 20.5 \%$; $30.2 \%, 20.5 \%$; and $27.5 \%, 20.3 \%$.

Table 2 shows that majority of the males (56.8\%) and females (47.3\%) were from the rural areas while $29.2 \%$ of the males and $38.7 \%$ were from urban villages. An overwhelming majority of the males $(88.7 \%)$ and females $(83.3 \%)$ had either no education or primary education. Only $2.4 \%$ of the males and $5.7 \%$ of the females had higher education. The percentages of the males and females who were in fulltime employment were $43.1 \%$ and $13.1 \%$, respectively. About one in every four males $(27 \%)$ and females $(27 \%)$ were working in their own land or cattle post. Only $3 \%$ of the males and $8 \%$ of the females were self-employed. Majority of the males (49.1\%) and females (51.2\%) were 
Citation: Ama NO, Dwivedi VK, Shaibu S, Burnette D (2015) Socio-Economic and Demographic Determinants of HIV Status among HIV Infected Older Adults (50-64 Years) In Botswana: Evidence From 2013 Botswana AIDS Impact Survey (BAIS IV). J AIDS Clin Res 6: 448. doi:10.4172/21556113.1000448

Page 4 of 9

\begin{tabular}{|c|c|c|c|c|c|c|c|}
\hline \multicolumn{3}{|c|}{ Sex of the respondent } & & \multicolumn{3}{|c|}{ Age in completed years } & \multirow[t]{2}{*}{ Total } \\
\hline & & & & $50-54$ & $55-59$ & $60-64$ & \\
\hline \multirow[t]{4}{*}{ Male } & Result of HIV test & POSITIVE & Number & 3123 & 4938 & 2005 & 10066 \\
\hline & & & & $19.8 \%$ & $30.2 \%$ & $27.5 \%$ & $25.5 \%$ \\
\hline & & NEGATIVE & Number & 12683 & 11386 & 5291 & 29360 \\
\hline & & & & $80.2 \%$ & $69.8 \%$ & $72.5 \%$ & $74.5 \%$ \\
\hline \multirow[t]{4}{*}{ Female } & Result of HIV test & POSITIVE & Number & 6261 & 4154 & 1823 & 12238 \\
\hline & & & & $22.7 \%$ & $20.5 \%$ & $20.3 \%$ & $21.5 \%$ \\
\hline & & NEGATIVE & Number & 21361 & 16094 & 7168 & 44623 \\
\hline & & & & $77.3 \%$ & $79.5 \%$ & $79.7 \%$ & $78.5 \%$ \\
\hline \multirow[t]{6}{*}{ Total } & Result of HIV test & POSITIVE & Number & 9384 & 9092 & 3828 & 22304 \\
\hline & & & & $21.6 \%$ & $24.9 \%$ & $23.5 \%$ & $23.2 \%$ \\
\hline & & NEGATIVE & Number & 34044 & 27480 & 12459 & 73983 \\
\hline & & & & $78.4 \%$ & $75.1 \%$ & $76.5 \%$ & $76.8 \%$ \\
\hline & Total & & Number & 43428 & 36572 & 16287 & 96287 \\
\hline & & & & $100.0 \%$ & $100.0 \%$ & $100.0 \%$ & $100.0 \%$ \\
\hline
\end{tabular}

Table 1: Result of HIV test by sex and age groups of older adults.

\begin{tabular}{|c|c|c|c|c|c|}
\hline & & \multicolumn{4}{|c|}{ Sex of the respondent } \\
\hline & & & & & \\
\hline \multicolumn{2}{|c|}{ Attributes of respondents } & Number & $\%$ & Number & $\%$ \\
\hline \multirow{4}{*}{ Type of locality } & Cities & 727 & 7.2 & 1326 & 10.8 \\
\hline & Towns & 687 & 6.8 & 387 & 3.2 \\
\hline & Urban Villages & 2939 & 29.2 & 4739 & 38.7 \\
\hline & Rural & 5713 & 56.8 & 5786 & 47.3 \\
\hline \multirow{6}{*}{ Highest education level } & None & 4792 & 47.6 & 3497 & 28.6 \\
\hline & Non- Formal & 134 & 1.3 & 61 & 0.5 \\
\hline & Primary & 4134 & 41.1 & 6690 & 54.7 \\
\hline & Junior Secondary & 761 & 7.6 & 1244 & 10.2 \\
\hline & Senior Secondary & 6 & 0.1 & 53 & 0.4 \\
\hline & Higher & 239 & 2.4 & 694 & 5.7 \\
\hline \multirow{9}{*}{ Employment status } & Full-time employed & 4336 & 43.1 & 1604 & 13.1 \\
\hline & Self-employed & 297 & 2.9 & 963 & 7.9 \\
\hline & Part-time employment & 416 & 4.1 & 292 & 2.4 \\
\hline & Working at own land/cattle post & 2721 & 27.0 & 3286 & 26.9 \\
\hline & Actively seeking work & 1090 & 10.8 & 993 & 8.1 \\
\hline & Too old to work & 0 & 0.0 & 1978 & 16.2 \\
\hline & Too sick to work & 533 & 5.3 & 985 & 8.0 \\
\hline & Pensioner & 244 & 2.4 & 453 & 3.7 \\
\hline & Student & 429 & 4.3 & 1684 & 13.8 \\
\hline \multirow{3}{*}{ Age in completed years } & $50-54$ & 3123 & 31.0 & 6261 & 51.2 \\
\hline & $55-59$ & 4938 & 49.1 & 4154 & 33.9 \\
\hline & $60-64$ & 2005 & 19.9 & 1823 & 14.9 \\
\hline
\end{tabular}


Citation: Ama NO, Dwivedi VK, Shaibu S, Burnette D (2015) Socio-Economic and Demographic Determinants of HIV Status among HIV Infected Older Adults (50-64 Years) In Botswana: Evidence From 2013 Botswana AIDS Impact Survey (BAIS IV). J AIDS Clin Res 6: 448. doi:10.4172/21556113.1000448

Page 5 of 9

\begin{tabular}{|c|c|c|c|c|c|}
\hline \multirow{6}{*}{ Marital status } & Married & 5119 & 50.9 & 2331 & 19.0 \\
\hline & Never married & 1719 & 17.1 & 5377 & 43.9 \\
\hline & Living together/cohabiting & 2188 & 21.7 & 1314 & 10.7 \\
\hline & Separated & 49 & 0.5 & 123 & 1.0 \\
\hline & Divorced & 113 & 1.1 & 654 & 5.3 \\
\hline & Widowed & 878 & 8.7 & 2440 & 19.9 \\
\hline \multirow[t]{2}{*}{ Husband/wife live with you } & Daily & 4806 & 65.8 & 2733 & 75.0 \\
\hline & Weekly & 2501 & 34.2 & 912 & 25.0 \\
\hline \multirow{2}{*}{$\begin{array}{l}\text { Taken an alcoholic drink in the } \\
\text { last } 12 \text { months }\end{array}$} & Yes & 3940 & 39.1 & 2744 & 22.4 \\
\hline & No & 6126 & 60.9 & 9494 & 77.6 \\
\hline \multirow{6}{*}{$\begin{array}{l}\text { Age when first married or started } \\
\text { living together }\end{array}$} & $10-19$ & 396 & 4.7 & 1622 & 23.6 \\
\hline & $20-29$ & 1538 & 18.4 & 2807 & 40.9 \\
\hline & $30-39$ & 2401 & 28.8 & 770 & 11.2 \\
\hline & $40-49$ & 3041 & 36.4 & 1341 & 19.6 \\
\hline & $50-59$ & 883 & 10.6 & 234 & 3.4 \\
\hline & $60-69$ & 87 & 1 & 87 & 1.3 \\
\hline \multirow{4}{*}{$\begin{array}{l}\text { Number of years married or } \\
\text { living together }\end{array}$} & $0-9$ & 4064 & 55.6 & 1703 & 46.7 \\
\hline & $10-19$ & 1563 & 21.4 & 421 & 11.5 \\
\hline & $20-29$ & 1681 & 23 & 992 & 27.2 \\
\hline & $30-39$ & 0 & 0 & 529 & 14.5 \\
\hline
\end{tabular}

Table 2: Characteristics of the older adults who are HIV by sex of older adult $(\mathrm{N}=22304)$

between age 55-59 years and 50-54 years respectively. About half of the males $(50.9 \%)$ and $19 \%$ of the females were married while majority of the females $(43.9 \%)$ were never married. About one in every five males $(21.7 \%)$ and $11 \%$ of the females were living together / cohabiting; $20 \%$ of the females were widowed. Of those who were married $(\mathrm{N}=7307$; $32.8 \%), 66 \%$ of the males and $75 \%$ of females live together and see each other daily while $34 \%$ of the males and $25 \%$ of the females meet weekly. Close to two in every five males (39.1\%) and one in every five females (22.4\%) had taken alcohol in the past 12 months. Majority of the males (65.2\%) first got married between age 30 and 49 years while $64.5 \%$ of the females first got married between age 10 and 29 years. Over half of the males $(55.6 \%)$ and $46.7 \%$ of the females have been married or living together less than 10 years, while only $23 \%$ of the males and $27.2 \%$ of the females have either been married or living together between 20 and 29 years (Table 2 ).

\section{Relationship between some socio-economic and demographic variables and HIV status of older adults $(\mathrm{N}=140,172)$}

In order to determine how socio-economic and demographic variables affected the HIV status of older adults, a multivariate binary logistic regression model was fitted to the data with the log odds of being HIV positive as the dependent variable and age in completed years, current marital status, sex of the older adults, age when first married or living together, number of years married or living together, employment status, highest level of education attained and type of locality as independent variables. The test statistic is the Wald Statistic, $\mathrm{W}=\mathrm{B} / \mathrm{S}$.E, where $\mathrm{B}$ is the regression coefficient and S.E. is the standard error of $\mathrm{B}$. The results of the analyses are shown in Table 3.

The table shows that all the socio-economic and demographic variables significantly $(\mathrm{p}<0.01)$ predict the probability of an older adult being HIV positive. The older adults living together/cohabiting are almost as likely to be HIV positive as the married (odds ratio $(\mathrm{OR})=0.94)$. Those who belong to Badimo religious group are 1.3 times more likely to be HIV positive than those who are Christians while those who do not belong to any religion are less likely to be HIV than the Christians. The older adults who got married at age 20-29 years, $30-$ 39 years and 50-59 years are about five times and 1.4 times, respectively, more likely to be HIV positive than those who got married between ages $10-19$ years. However, marrying at age $40-49$ years is negatively correlated with being HIV positive $(B=-0.235)$.

Older adults who have been married for 10-19 years, 30-39 years are about 2.6 times and 1.7 times, respectively, more likely to be HIV positive than those who have been married for 0-9 years. Age in completed years is negatively correlated with being HIV positive (B is less than zero). Thus, older adults in the age range 55-59 years and 6064 years are 0.6 times, and 0.7 times, respectively as likely to be HIV positive as those aged $50-54$ years.

Employment, as a proxy for income, is a significant predictor HIV status among older adults. Compared with those who have full-time employment, the self-employed and those too old to work (this might represent the retirees) are 1.3 times and 1.8 times, respectively, more likely to be HIV positive. Otherwise, the older adults in the other categories of employment are less likely to be HIV positive.

There is a tendency for older adults with increased level of education to become infected with HIV. The results show that those with non-formal and primary education are less likely to be HIV positive than older adults with education. The older adults with secondary education and higher education are respectively, 65.5 times and 1.8 times more likely to be HIV positive. Type of locality has significant impact in the determination of 
Citation: Ama NO, Dwivedi VK, Shaibu S, Burnette D (2015) Socio-Economic and Demographic Determinants of HIV Status among HIV Infected Older Adults (50-64 Years) In Botswana: Evidence From 2013 Botswana AIDS Impact Survey (BAIS IV). J AIDS Clin Res 6: 448. doi:10.4172/21556113.1000448

Page 6 of 9

\begin{tabular}{|c|c|c|c|c|c|c|c|}
\hline $\begin{array}{l}\text { Reference } \\
\text { Category }\end{array}$ & Variables & B & S.E. & Wald & df & Sig. & $\operatorname{Exp}(B)$ \\
\hline \multirow[t]{2}{*}{ Married } & Marital status (living together) & -0.064 & 0.015 & 19.16 & 1 & 0 & 0.938 \\
\hline & Main religious affiliation & & & 134.681 & 5 & 0 & \\
\hline \multirow[t]{2}{*}{ Christianity } & Badimo & 0.257 & 0.062 & 17.269 & 1 & 0 & 1.293 \\
\hline & No religion & -0.468 & 0.045 & 109.647 & 1 & 0 & 0.626 \\
\hline \multirow[t]{2}{*}{ Male } & Sex of the respondent & 0.912 & 0.03 & 896.143 & 1 & 0 & 2.489 \\
\hline & Age when first married or started living together & & & 1410.57 & 5 & 0 & \\
\hline \multirow[t]{5}{*}{$10-19$} & $20-29$ & 1.555 & 0.059 & 700.643 & 1 & 0 & 4.737 \\
\hline & $30-39$ & 0.32 & 0.092 & 12.124 & 1 & 0 & 1.378 \\
\hline & $40-49$ & -0.235 & 0.108 & 4.724 & 1 & 0.03 & 0.791 \\
\hline & $50-59$ & 0.319 & 0.12 & 7.007 & 1 & 0.008 & 1.375 \\
\hline & Number of years married or living together & & & 863.495 & 3 & 0 & \\
\hline \multirow[t]{4}{*}{$0-9$} & $10-19$ & 0.935 & 0.055 & 286.92 & 1 & 0 & 2.546 \\
\hline & $20-29$ & -0.345 & 0.089 & 15.223 & 1 & 0 & 0.708 \\
\hline & $30-39$ & 0.532 & 0.121 & 19.223 & 1 & 0 & 1.702 \\
\hline & Age in completed years & & & 324.676 & 2 & 0 & \\
\hline \multirow[t]{3}{*}{$50-54$} & $55-59$ & -0.588 & 0.033 & 315.732 & 1 & 0 & 0.556 \\
\hline & $60-64$ & -0.348 & 0.045 & 59.392 & 1 & 0 & 0.706 \\
\hline & Employment status & & & 1901.57 & 8 & 0 & \\
\hline \multirow[t]{9}{*}{ Full-time employed } & Self-employed & 0.288 & 0.05 & 33.186 & 1 & 0 & 1.334 \\
\hline & Part-time employed & -0.682 & 0.073 & 87.716 & 1 & 0 & 0.506 \\
\hline & Working at own land/cattle post & -0.159 & 0.034 & 22.418 & 1 & 0 & 0.853 \\
\hline & Actively seeking work & -0.818 & 0.057 & 204.877 & 1 & 0 & 0.441 \\
\hline & Too old to work & 0.562 & 0.077 & 53.757 & 1 & 0 & 1.754 \\
\hline & Too sick to work & -1.395 & 0.07 & 398.397 & 1 & 0 & 0.248 \\
\hline & Pensioner & -2.946 & 0.084 & 1219.57 & 1 & 0 & 0.053 \\
\hline & Student & -0.074 & 0.053 & 1.943 & 1 & 0.163 & 0.929 \\
\hline & Highest level of education you completed & & & 1326.39 & 5 & 0 & \\
\hline \multirow[t]{6}{*}{ None } & Non-formal & -1.08 & 0.11 & 97.066 & 1 & 0 & 0.339 \\
\hline & Primary & -0.74 & 0.029 & 630.566 & 1 & 0 & 0.477 \\
\hline & Junior Secondary & 0.05 & 0.052 & 0.9 & 1 & 0.343 & 1.051 \\
\hline & Senior Secondary & 4.182 & 0.424 & 97.41 & 1 & 0 & 65.496 \\
\hline & Higher & 0.562 & 0.054 & 108.278 & 1 & 0 & 1.754 \\
\hline & Type of locality & & & 340.821 & 3 & 0 & \\
\hline \multirow[t]{3}{*}{ Cities } & Towns & 0.12 & 0.071 & 2.85 & 1 & 0.091 & 1.127 \\
\hline & Urban Villages & -0.013 & 0.05 & 0.064 & 1 & 0.801 & 0.987 \\
\hline & Rural & -0.504 & 0.049 & 106.565 & 1 & 0 & 0.604 \\
\hline Daily & Does your husband/wife live with you? (Weekly) & -1.257 & 0.053 & 564.502 & 1 & 0 & 0.285 \\
\hline Yes & $\begin{array}{l}\text { Have you taken an alcoholic drink in the last } 12 \\
\text { months? NO }\end{array}$ & -0.468 & 0.056 & 69.351 & 1 & 0 & 0.626 \\
\hline Yes & Are you circumcised?(NO) & -1.323 & 0.054 & 598.082 & 1 & 0 & 0.266 \\
\hline \multirow[t]{2}{*}{ Yes } & $\begin{array}{l}\text { In the past four weeks, have you heard or seen any } \\
\text { information about HIVIAIDS?(No) }\end{array}$ & -0.115 & 0.055 & 4.323 & 1 & 0.038 & 0.892 \\
\hline & Constant & 1.49 & 0.107 & 192.292 & 1 & 0 & 4.439 \\
\hline
\end{tabular}

Table 3: Logistic regression model to predict impact of socio-economic and demographic variables on HIV status of older adults.

HIV status of the older adults. The older adults who dwell in the towns are 1.1 times as likely to be HIV positive as those in the cities whereas those from rural areas or villages are less likely to be infected with HIV than those in the cities. Those married or co-habiting older adults who see each other weekly, have not taken any alcoholic drinks over the past 12 months before the study or in the past four weeks, before the study have not heard or seen any information about HIV and AIDS are less likely to be HIV positive than those meet each other daily, drink alcohol or have heard some information about HIV and AIDS, respectively Contrary to expectation, older adults who are not circumcised are less likely to be HIV positive than those who are circumcised.

Test of socio-economic status versus risk behaviour and service received

Table 4 summarizes the association between the older adults' highest educational level, employment status, marital status, age and 
Citation: Ama NO, Dwivedi VK, Shaibu S, Burnette D (2015) Socio-Economic and Demographic Determinants of HIV Status among HIV Infected Older Adults (50-64 Years) In Botswana: Evidence From 2013 Botswana AIDS Impact Survey (BAIS IV). J AIDS Clin Res 6: 448. doi:10.4172/21556113.1000448

Page 7 of 9

\begin{tabular}{|l|c|c|c|}
\hline Variables & Chi-square & df & P-value \\
\hline Highest educational level versus condom use & 2097.318 & 15 & 0.00 \\
\hline Employment Status versus condom use & 4024.078 & 24 & 0.00 \\
\hline Marital Status versus condom use & 1532.851 & 6 & 0.396 \\
\hline Age in completed years versus condom use & 651.585 & 9 & 0.513 \\
\hline Type of locality versus condom use & 778.805 & 5 & 0.00 \\
\hline Highest educational level versus ARV & 147.075 & 8 & 0.00 \\
\hline Employment Status versus ARV & 812.506 & 5 & 0.00 \\
\hline Marital Status versus ARV & 335.59 & 2 & 0.00 \\
\hline Age in completed years versus ARV & 37.634 & 0.117 \\
\hline Type of locality versus ARV & 122.856 & 0.00 \\
\hline
\end{tabular}

Table 4: Summary of analysis of inter-relationship between some socio-economic variables and key risky behaviour and treatment for HIV and AIDS among older HIV infected adults.

type of locality and the use of condom (risk behaviour) and utilization of ARV for the treatment of HIV and AIDS.

The Pearson's contingency coefficient, which has been calculated, is one method to provide an easier to interpret measure of strength of association. Specifically, it is:

Pearson's Coefficient $=\sqrt{\frac{T}{N+T}}$
where

$T=$ the chi-square test statistic and $N=$ the total sample size

So this statistic basically scales the chi-square statistic to a value between 0 (no association) and 1 (maximum association). It has the desirable property of scale invariance. That is, if the sample size increases, the value of Pearson's contingency coefficient does not change as long as values in the table change the same relative to each other.

The results show that there are significant association between the socio-economic and demographic variables and the risk behaviour as shown by their condom use and treatment of HIV as illustrated by their knowledge and use of ART $(p<0.01)$. The association between employment and condom use is strong; moderate association between highest level of education, marital status and condom use and weak association between age, type of locality and condom use. Generally, the association between the variables and use of ARV is very weak.

The results of analyses show that there are significant correlations between HIV status and sex of the older adults $(\mathrm{r}=0.04, \mathrm{p}<0.01$, $\mathrm{n}=96288)$, locality $(\mathrm{r}=-0.073, \mathrm{p}<0.01, \mathrm{n}=96288)$ and sexual activity $(\mathrm{r}=0.038, \mathrm{p}<0.01, \mathrm{n}=96288)$.

\section{Discussion of Results and Conclusions}

The paper set as its objectives to determine the socio-economic and demographic characteristics of the older adults with HIV in Botswana and show how these variables influence the HIV status of the older adults, using the 2013 BAIS IV data. The analyses and subsequent results were based on the older adults infected with HIV.

The results of the analysis revealed an overall HIV prevalence rate of $23.2 \%$ among the older adults with prevalence rates of $25.5 \%$ among the males and $21.5 \%$ among the females. The age group HIV prevalence rates were $21.6 \%, 24.9 \%$ and $23.5 \%$ for the $50-54,55-59$ and $60-64$ yearolder adults, respectively. The HIV prevalence for males and females were $19.8 \%$ and $22.7 \%$ in $50-54$ year-olds, $30.2 \%$ and $20.5 \%$ in $55-59$ year-olds and $27.5 \%$ and $20.3 \%$ in $60-64$ year-olds, respectively. These values are very much higher than the overall prevalence of $9.5 \%$ with 29.5\% for males and $17.3 \%$ for females for South Africa reported by
Wallrauch et al. [30] and the age specific HIV prevalence for males and females of $10.4 \%$ and $10.2 \%$ in $50-54$ year-olds, $6.2 \%$ and $7.7 \%$ in $55-59$ year-olds and $3.5 \%$ and $1.8 \%$ in 60 years and over, respectively, reported by Shishana et al. [42]. These results have high implications in the burdens of HIV epidemic upon the older adults and in the performance of their roles as caretakers of their adult HIV-infected children and orphaned children as older adults are largely neglected in the targeting of the HIV response. There is little evidence to help in deciding on the optimum treatment regimen in older people [43].

More of the older adult males (50.7\%) than the females (19\%) were married and of these proportions $34 \%$ of the males and $25 \%$ of the females meet with their spouses only weekly. The percentages that were living together/cohabiting (not properly married) were $21.7 \%$ of the males and $11 \%$ of the females. The overwhelming majority of the older adult males $(88.7 \%)$ and females $(83.3 \%)$ had primary or no education while only $43.1 \%$ of the males and $13.1 \%$ of the females were in fulltime employment. The older adults were predominantly from either urban villages or rural areas ( $86 \%$ for males as well as females). The low level of education has implications in knowledge of and accessing information on issues about HIV and AIDS and related matters. The high percentage of the older adults in either self-employment or not working explains why older adults, particularly women, have become so important in caregiving for people living with HIV and AIDS, TB, chronic diseases such as stroke, cancer etc, particularly for family members [3]. The profile of the patients on Community Home Based programs in Botswana has changed with the advent of ARVs, reflecting the epidemiological transition where there is an increase of non-communicable diseases (NCDs) along infectious diseases. It is eminent, therefore, that as a caregiver, one should be knowledgeable and economically viable to be able to offer the desired services (e.g financial assistance; being able to read prescription, review dates and other information meant for the patient).

The roles of the older adults as care givers, educators, advisors to their adult children and grandchildren or active community members $[3,44]$ could be hampered, therefore, by their little education and high level of unemployment, when employment is seen as proxy for income. The low level of education among older adults also has implications for strategies that will take into consideration the health literacy of this aggregate, as well as tailoring culturally sensitive messages, which take into cognisance the communication of matters of sexuality to them.

Poverty which is a direct derivative of lack of employment has been viewed as a social driver in HIV epidemics and may have been contributory to the high prevalence rate. However, this view has been challenged by authors [45-47] who have illustrated that in many subSaharan African countries, it is the wealthier groups that often have 
Citation: Ama NO, Dwivedi VK, Shaibu S, Burnette D (2015) Socio-Economic and Demographic Determinants of HIV Status among HIV Infected Older Adults (50-64 Years) In Botswana: Evidence From 2013 Botswana AIDS Impact Survey (BAIS IV). J AIDS Clin Res 6: 448. doi:10.4172/21556113.1000448

Page 8 of 9

higher HIV prevalence rates and in many African countries, the wealthier countries tend to report higher national prevalence rates [46]. These findings explain why almost all levels of employment status are negatively correlated with being HIV positive $(\mathrm{B}<0)$ in the analysis (Table 3).

The analysis shows that the higher the level of education, the more likely the older adults become HIV positive showing that acquisition of higher education does not necessarily guarantee prevention from HIV infection as such education may not necessarily be directed towards HIV and AIDS awareness, prevention and treatment. Stombeck and Levy [38] noted that education is the best strategy for the prevention of HIV and AIDS among older adults. Such prevention and education initiatives must include peer education, media awareness campaigns, group workshops, publications for mass consumption, individual and couple counselling and safe injection sites [39]. Major challenges to providing education for HIV and AIDS prevention among older adults were reported as as health professional ageism (that is, misconception by health professionals and the general public that older adults are not at risk of HIV and AIDS, that older adults are asexual and that targeting HIV and AIDS prevention programs for the older adults is futile), older adults' reluctance to discuss sexuality and their misconceptions of their HIV risk [48]. It is, therefore, important that education aimed at equipping the older adults to prevent themselves from being infected by HIV be provided to them should be culturally sensitive and use for example senior peers [29].

The study findings show that older adults in the towns are about 1.1 times more likely to be HIV positive than those in the cities but those from the urban villages or rural areas are less likely to be HIV positive. The results are consistent with the overall HIV prevalence among cities, towns and rural populations in Botswana from the 2008 BAIS III and 2013 BAIS IV which show that Towns have the highest HIV prevalence, followed by the cities, urban and rural areas (Statistics Botswana, 2013). Also, Druyts (2009) found out in Canada that the highest incidence and mortality from HIV/AIDS occurs within the urban centres of Vancouver, Toronto and Montreal.

The study results show that $49.9 \%$ of the male older adults and $81 \%$ of the female older adults were unmarried. In addition, $25.5 \%$ of the males and $21.5 \%$ of the females were HIV positive. The logistic regression analysis shows that those not married were slightly significantly less likely to be HIV positive than the married older adults. Thus marital status can be seen as a significant risk factor for HIV infection. This finding supports those of Kposowa [49] who found that in the United States marital status was a significant risk factor for men, although not women. However, and contrary to the results in this study, Kposowa [49] showed that divorced and separated men were more than six times more likely to die of AIDS than married men, and those who had never married were 13.5 times more likely to die of the disease than those who were married. Since the major transmission of $\mathrm{HIV}$ in Botswana is through sexual activity, marriage is supposed to add buffering and other advantages than other marital status, since the married person is expected to rely on one partner but the results point to the possibility of multiple partners. The UNGASS [50] indicated that throughout Botswana certain traditions have been shown to increase the risk of HIV infection between people in long-term heterosexual relationships. One of these is the culturally accepted tradition of men having multiple and concurrent partnerships, as well as the common practice of inter-generational relationships and/or marriage. Within this context, women and young girls experience difficulty negotiating condom use, or refusing sex. This may have greatly increased the risk of onward HIV transmission among married couples.

\section{Conclusions}

It is clear from the findings of the study that older female adults are marginalized in employment and being married has not positively impacted on the reduction on HIV prevalence possibly because of the some accepted traditional beliefs. A lot of the older adults are not educated and this is likely to impact on their role as caregivers and their ability to prevent themselves from contracting the disease. Even where they are educated, such education is unlikely to be focussed on prevention and education initiatives for HIV and AIDS, which include peer education, media awareness campaigns, group workshops, publications for mass consumption, individual and couple counselling. The fact that older adults in rural areas are less likely to be HIV positive shows that a lot more of the intervention messages for HIV prevention should also address the needs of the urban areas, towns and cities.

\section{Recommendations}

\section{The paper recommends the following:}

- The recognition of the older adults as one of the vulnerable groups/key populations that requires special attention on issues of HIV and AIDS and other health related matters. Specifically, the older adults (particularly those who are HIV positive) in Botswana need to be provided with support systems that will help them overcome the stigma associated with HIV and AIDS.

- Increased access to information and education on the risk of HIV and AIDS, so that they can protect themselves and others against infection with HIV. Such information should take into consideration the low level of educational attainment of this group as well as be culturally sensitive to discussing issues of sexuality that are treated as taboo. Use of toolkits containing the necessary information in Setswana can be dropped at their doorsteps. The education and prevention initiatives should employ peer education, media awareness campaigns, group workshops, publications for mass consumption, individual and couple counselling.

- Specific prevention messages that are age-specific and culturally oriented for the older adults should be developed, since currently such HIV messages target only those 15-49 years.

\section{References}

1. Mutevedzi PC, Newell ML (2011) A missing piece in the puzzle: HIV in mature adults in sub-Saharan Africa. Future Virol 6: 755-767.

2. UNAIDS (2013) HIV and Aging: A special supplement to the UNAIDS report on the global AIDS epidemic 2013. Joint United Nations Programme on HIV/ AIDS (UNAIDS)

3. Negin J, Cumming RG (2010) HIV infection in older adults in sub-Saharan Africa: extrapolating prevalence from existing data. Bull World Health Organ 88: 847-853.

4. UNGASS (2010) Botswana UNGASS Country Report 2010

5. Williams E, Donnelly J (2002) Older Americans and AIDS: some guidelines for prevention. Soc Work 47: 105-111.

6. Sankar A, Nevedal A, Neufeld S, Berry R, Luborsky M (2011) What do we know about older adults and HIV? A review of social and behavioral literature. AIDS Care 23: 1187-1207.

7. Goetz MB, Boscardin WJ, Wiley D, Alkasspooles S (2001) Decreased recovery of CD4 lymphocytes in older HIV-infected patients beginning highly active antiretroviral therapy. AIDS 15: 1576-1579.

8. Njie-Carr VP (2009) Knowledge, attitudes, cultural, social and spiritual beliefs 
Citation: Ama NO, Dwivedi VK, Shaibu S, Burnette D (2015) Socio-Economic and Demographic Determinants of HIV Status among HIV Infected Older Adults (50-64 Years) In Botswana: Evidence From 2013 Botswana AIDS Impact Survey (BAIS IV). J AIDS Clin Res 6: 448. doi:10.4172/21556113.1000448

Page 9 of 9

on healthseeking behaviors of Gambian adults with HIVIAIDS. Int J Cult Ment Health 2: 118-128.

9. Foster V, Clark PC, Holstad MM, Burgess E (2012) Factors associated with risky sexual behaviors in older adults. J Assoc Nurses AIDS Care 23: 487-499.

10. Smith RD, Delpech VC, Brown AE, Rice BD (2010) HIV transmission and high rates of late diagnoses among adults aged 50 years and over. AIDS 24: 21092115 .

11. CDC (2008) HIV and AIDS among persons aged 50 and older. CDC HIV and AIDS facts, February 2008

12. Zablotsky D, Kennedy M (2003) Risk factors and HIV transmission to midlife and older women: knowledge, options, and the initiation of safer sexual practices. J Acquir Immune Defic Syndr 33 Suppl 2: S122-130.

13. Jacobs RJ, Thomlison B (2009) Self-silencing and age as risk factors for sexually acquired HIV in midlife and older women. J Aging Health 21: 102-128.

14. Ances BM, Vaida F, Yeh MJ, Liang CL, Buxton RB, et al. (2010) HIV infection and aging independently affect brain function as measured by functional magnetic resonance imaging. J Infect Dis 201: 336-340.

15. DAD Study Group, Friis-Møller N, Reiss P, Sabin CA, Weber R, et al. (2007) Class of antiretroviral drugs and the risk of myocardial infarction. N Engl J Med 356: $1723-1735$

16. Monforte Ad, Abrams D, Pradier C, Weber R, Reiss P, et al. (2008) HIV-induced immunodeficiency and mortality from AIDS-defining and non-AIDS-defining malignancies. AIDS 22: 2143-2153.

17. Valcour V, Shikuma C, Shiramizu B, Watters M, Poff P, et al. (2004) Higher frequency of dementia in older HIV-1 individuals: the Hawaii Aging with HIV-1 Cohort. Neurology 63: 822-827.

18. Grabar S, Kousignian I, Sobel A, Le Bras P, Gasnault J, et al. (2004) Immunologic and clinical responses to highly active antiretroviral therapy over 50 years of age. Results from the French Hospital Database on HIV. AIDS 18 2029-2038.

19. Kuteesa M, Seeley J, Cumming RG, Negin J (2012) Older people living with HIV in Uganda: Understanding their experience and needs. African Journal of AIDS Research 11: 295-305.

20. Nokes KM, Holzemer WL, Corless IB, Bakken S, Brown M, et al. (2000) Health related quality of life in persons younger and older than 50 who are living with HIVIAIDS. Research on Aging 22: 290-310.

21. Schoenborn CA, Heyman KM (2009) Health characteristics of adults aged 55 years and over: United States, 2004-2007. Natl Health Stat Report : 1-31.

22. Statistics Botswana (2013) Preliminary Results Botswana AIDS Impact Survey IV (BAIS IV). Government Printers, Gaborone.

23. Gebo KA (2008) Epidemiology of HIV and response to antiretroviral therapy in the middle aged and elderly. Aging health 4: 615-627

24. Herbst AJ, Cooke GS, Bärnighausen T, KanyKany A, Tanser F, et al. (2009) Adult mortality and antiretroviral treatment roll-out in rural KwaZulu-Natal, South Africa. Bull World Health Organ 87: 754-762.

25. Manfredi R, Calza L, Cocchi D, Chiodo F (2003) Antiretroviral treatment and advanced age: epidemiologic, laboratory, and clinical features in the elderly. $J$ Acquir Immune Defic Syndr 33: 112-114.

26. Grabar S, Weiss L, Costagliola D (2006) HIV infection in older patients in the HAART era. J Antimicrob Chemother 57: 4-7.

27. Nguyen N, Holodniy M (2008) HIV infection in the elderly. Clin Interv Aging 3 453-472.

28. Schmid GP, Williams BG, Garcia-Calleja JM, Miller C, Segar E, et al. (2009) The unexplored story of HIV and ageing. Bull World Health Organ 87: 162$162 \mathrm{~A}$.

29. Tlou S (1996) Empowering older women in HIV prevention: The case of Botswana. Southern African Journal of Gerontology 5: 27-32.

30. Wallrauch C, Bärnighausen T, Newell ML (2010) HIV prevalence and incidence in people 50 years and older in rural South Africa. S Afr Med J 100: 812-814.

31. Peltzer K, Phaswana-Mafuya N, Mzolo T, Tabane C, Zuma K (2010) Sexual behaviour, HIV status and HIV risk among older South Africans. Ethno Med 4: 163-172.
32. Cunningham WE, Hays RD, Duan N, Andersen R, Nakazono TT, et al. (2005) The effect of socioeconomic status on the survival of people receiving care for HIV infection in the United States. J Health Care Poor Underserved 16 $655-676$.

33. Commission on Social Determinants of Health (CSDH) (2008) Closing the gap in a generation: health equity through action on the social determinants of health. Final report of the Commission on Social Determinants of Health. World Health Organization, Geneva.

34. Silva-Santisteban A, Segura ER, Sandoval C, Girón M, Petrera M, et al. (2013) Determinants of unequal HIV care access among people living with HIV in Peru. Global Health 9: 22.

35. Perry MJ (1998) Gender, race and economic perspectives on the socia epidemiology of HIV infection: Implications for prevention. The Journal of Primary Prevention 19: 97-104.

36. Institute of Medicine (US) Committee on the Review and Assessment of the NIH's Strategic Research Plan and Budget to Reduce and Ultimately Eliminate Health Disparities; Thomson GE, Mitchell F, Williams MB (2006) Examining the Health Disparities Research Plan of the National Institutes of Health: Unfinished Business. National Academies Press, Washington, DC

37. Ickovics JR, Beren SE, Grigorenko EL, Morrill AC, Druley JA, et al. (2002) Pathways of risk: Race, social class, stress, and coping as factors predicting heterosexual risk behaviors for HIV among women. AIDS and Behavior 6: 339350

38. Strombeck R, Levy JA (1998) Educational Strategies and Interventions Targeting Adults Age 50 and Older for HIVIAIDS Prevention. Research on Aging 20: 912-936.

39. Milaszewski D, Greto E, Klochkov T, Fuller-Thomson E (2012) A systematic review of education for the prevention of HIVIAIDS among older adults. J Evid Based Soc Work 9: 213-230.

40. Aidala A, Cross JE, Stall R, Harre D, Sumartojo E (2005) Housing status and HIV risk behaviors: implications for prevention and policy. AIDS Behav 9: 251 265.

41. Culhane D, Gollub E, Kuhn R, Shpaner M (2001) The co-occurrence of AIDS and homelessness: results from the integration of administrative databases for AIDS surveillance and public shelter utilisation in Philadelphia. J Epidemio Community Health 55: 515-520.

42. Shisana O, Rehle T, Simbayi LC, Zuma K, Jooste S (2009) South African national prevalence, incidence, behaviour and communication survey: a turning tide among teenagers? Cape Town: HSRC Press, 116.

43. Gebo KA (2009) HIV infection in older people. BMJ 338: b1460

44. WHO (2002) Impact of AIDS on Older People in Africa: Zimbabwe Case Study. World Health Organisation, Switzerland, Geneva.

45. Shelton JD, Cassell MM, Adetunji J (2005) Is poverty or wealth at the root of HIV? Lancet 366: 1057-1058.

46. Chin J (2007) The AIDS pandemic: the collision of epidemiology with political correctness. Oxford: Radcliffe

47. Mishra V, Assche SB, Greener R, Vaessen M, Hong R, et al. (2007) HIV infection does not disproportionately affect the poorer in sub-Saharan Africa. AIDS 21 Suppl 7: S17-28.

48. Altschuler J, Katz AD, Tynan M (2004) Developing and implementing an HIV/ AIDS educational curriculum for older adults. Gerontologist 44: 121-126.

49. Kposowa AJ (2013) Marital status and HIVIAIDS mortality: evidence from the US National Longitudinal Mortality Study. Int J Infect Dis 17: e868-874.

50. UNGASS (2012) UNGASS Country Report 2012 